\title{
Combined analysis of VEGF and EGFR predicts complete tumour response in rectal cancer treated with preoperative radiotherapy
}

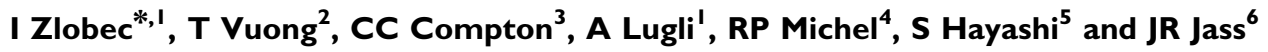 \\ 'Institute of Pathology, University Hospital of Basel, Schönbeinstrasse 40, Basel 4031, Switzerland; ' Department of Radiation Oncology, McGill University \\ Health Centre, 1650 Cedar Avenue, Montreal, QC, Canada H3G IA4; ${ }^{3}$ Office of Biorepositories and Biospecimen Research, National Cancer Institute, \\ National Institutes of Health, 3 I Center Drive, Bethesda, MD 20892, USA; ${ }^{4}$ Department of Pathology, McGill University, 3775 University Street, \\ Montreal, QC, Canada H3A 2B4; ${ }^{5}$ Department of Pathology, Toyama University, 2630 Sugitani, Toyama 930-0194, Japan; ${ }^{6}$ Department of Cellular \\ Pathology, St Mark's Hospital, Imperial College London, Watford Road, Middlesex HAI 3UJ, UK
}

The ability to predict complete pathologic response or sensitivity to radiation before treatment would have a significant impact on the selection of patients for preoperative radiotherapy or chemo-radiation therapy schedules. The aim of this study was to determine the value of epidermal growth factor receptor (EGFR), vascular endothelial growth factor (VEGF), p53, Bcl-2 and apoptosis proteaseactivating factor-I (APAF-I) as predictors of complete pathologic tumour regression in patients undergoing preoperative radiotherapy for advanced rectal cancer. Pretreatment tumour biopsies from predominantly cT3 patients undergoing a preoperative high-dose-rate brachytherapy protocol were immunostained for EGFR, VEGF, p53, Bcl-2 and APAF-I. Immunoreactivity was evaluated by three pathologists. Cut-off scores for tumour marker positivity were obtained by receiver-operating characteristic (ROC) curve analysis. The association of marker expression with complete pathologic response was analysed in univariate and multivariable analysis. Multi-marker phenotypes of the independent protein markers were evaluated. In multivariable analysis, loss of VEGF $(P$-value $=0.009$; odds ratio $(\mathrm{OR})(95 \% \mathrm{Cl})=0.24(0.08-0.69))$ and positive EGFR $(P$-value $=0.0 \mathrm{l}$; OR $(95 \% \mathrm{Cl})=3.82$ $(1.37-10.6))$ both demonstrated independent predictive value for complete pathologic response. The odds of complete response were 12.8 for the multi-marker combination of VEGF-negative and EGFR-positive tumours. Of the 34 EGFR-negative- and VEGFpositive cases, 32 (94. I\%) had no complete pathologic response. The combined analysis of VEGF and EGFR is predictive of complete pathologic response in patients undergoing preoperative radiotherapy. In addition, the findings of this study have identified a subgroup of simultaneous EGFR-negative and VEGF-positive patients who are highly resistant to radiotherapy and should perhaps be considered candidates for innovative neoadjuvant combined modalities.

British Journal of Cancer (2008) 98, 450-456. doi:I0.1038/sj.bjc.6604I72 www.bjcancer.com

Published online 8 January 2008

(c) 2008 Cancer Research UK

Keywords: rectal cancer; VEGF; EGFR; immunohistochemistry; pre-operative radiotherapy; brachytherapy

Colorectal cancer is a leading cause of cancer-related mortality and morbidity in the Western world, with 5-year survival rates ranging from 90 to $10 \%$ with tumour progression (O'Connell et al, 2004). Patients with rectal cancers, comprising approximately $30 \%$ of these cases, are known to have an increased rate of local recurrence and decreased survival time compared with patients with tumours of the colon, a result due primarily to the surgical constraints imposed by the location of the rectum within the pelvis (Wolpin et al, 2007). As a consequence, the clinical management of patients with rectal cancer differs significantly from that of the colon in terms of surgical technique, the more frequent use of radiotherapy and method of chemotherapy administration.

Evidence from randomised clinical trials, meta-analyses and epidemiologic studies strongly support the treatment of rectal cancer with preoperative modalities (Colorectal Cancer Collaborative

*Correspondence: Dr I Zlobec; E-mail: izlobec@uhbs.ch Received 24 September 2007; revised 29 November 2007; accepted 29 November 2007; published online 8 January 2008
Group, 2001; Wong et al, 2007). The Swedish Rectal Cancer Trial was the first to demonstrate an independent survival benefit and significant improvement in local control with preoperative short-course radiotherapy ( $25 \mathrm{~Gy}$ delivered in five fractions over 1 week) compared with surgery alone (Swedish Rectal Cancer Trial Group, 1997). Similar findings were derived from the Stockholm II Trial with the same fractionation regimen (Martling et al, 2001). Recently, short-course preoperative radiotherapy was found to decrease these rates even further in combination with total mesorectal excision (TME) (Kapiteijn et al, 2001). Short-course continuous, hyperfractionated, accelerated radiation therapy (CHART) and conformal high-dose-rate endorectal brachytherapy (HDREB) have demonstrated high rates of complete pathologic response as well as acceptable toxicity levels and tolerable side effects (Vuong et al, 2002, 2007; Brooks et al, 2006).

Several pathological features have been identified as prognostic factors in patients undergoing preoperative radiotherapy with or without chemotherapy. The circumferential resection margin status significantly affects prognosis with 5-year overall- and 
recurrence-free survival, decreasing substantially with increasing R-stage (den Dulk et al, 2007; Eriksen et al, 2007; Larsen et al, 2007). Rödel and co-workers investigated the tumour regression grade (TRG) on 5-year disease-free survival in more than 350 patients (Rodel et al, 2005). An independent adverse prognostic effect was observed in patients with low TRG. Kuo et al (2007) noted an improved survival in patients with complete pathologic response and a decreased prognosis in patients with more advanced post-treatment TNM stage. Das et al (2007) observed an association between complete pathologic response and locoregional control.

In addition to these pathological prognostic factors, which can only be identified post-surgically, molecular characterisation is expected to improve the identification of more aggressive or treatment-resistant tumours before therapy. Recently, microarray gene expression profiling was successfully used to predict complete responses to preoperative chemoradiotherapy with advanced-stage rectal cancer (Ghadimi et al, 2005; Kim et al, 2007). Epidermal growth factor receptor (EGFR), vascular endothelial growth factor (VEGF), the p53 tumour suppressor and key mediators of cell-cycle arrest (p21, p27) and apoptosis (Bcl-2, apoptosis protease-activating factor-1 (APAF-1)) are among the immunohistochemical protein markers currently of interest as potential predictors of pathologic response, prognosis and recurrence-free survival in rectal cancer following neoadjuvant therapy (Giralt et al, 2005, 2007; Lopez-Crapez et al, 2005; Kim et al, 2006; Lin et al, 2006; Smith et al, 2006; Bertolini et al, 2007).

The aim of this study was to predict complete pathological tumour regression to preoperative HDREB by investigating the combined immunohistochemical expression of EGFR, VEGF, p53, Bcl-2 and APAF-1 in 104 pretreatment biopsies from patients with advanced rectal cancer.

\section{MATERIALS AND METHODS}

\section{Preoperative HDREB}

This study was approved by the Research Ethics Committee of the McGill University Health Center. One hundred and four patients with newly diagnosed invasive, resectable rectal adenocarcinoma were included in this study and informed written consent was obtained. Preoperative staging was performed according to the International Union against Cancer Classification and carried out by endorectal ultrasonography and magnetic resonance imaging (MRI). Eligible patients included those with large $\mathrm{T} 2$ tumours located in the middle $1 / 3$ of the rectum, T3 and early T4 tumours. Patients with abdominal nodal disease, metastases and small T2 tumours with favourable features were excluded from the study. Tumour sizes ranged from 3 to $5 \mathrm{~cm}$ in diameter. Radiation was delivered preoperatively with a multichannel endorectal applicator (Novi Sad and recently with the Oncosmart Nucleotron B.V., Veenendaal, Netherlands) and a highdose-rate remote after-loading system using an Iridium-192 source (Vuong et al, 2007). A daily fraction of $6.5 \mathrm{~Gy}$ was administered over four consecutive days up to a total of $26 \mathrm{~Gy}$. Each patient was planned with endorectal applicator in place using a CT simulator (Pickler International Inc., Highland Heights, OH, USA) in order to obtain optimal conformal dosimetry. The dose was prescribed to a clinical target volume that included the gross tumour volume and any intramesorectal deposits visible at MRI. Patients underwent surgery 4-8 weeks after brachytherapy as planned before treatment regardless of tumour response.

The assessment of tumour response was performed by pathologic evaluation of rectal specimens postoperatively. Tumours considered to be completely responsive to preoperative HDREB had no histologic evidence of residual viable carcinoma (ypT0). Tumours with microfoci, foci or large areas of residual carcinoma were considered partially or non-responsive to treatment.

\section{Immunohistochemistry}

Immunohistochemistry for EGFR, VEGF, p53, Bcl-2 and APAF-1 was carried out on formalin-fixed, paraffin-embedded serial sections cut at $3 \mu \mathrm{m}$ and dried at $37^{\circ} \mathrm{C}$ overnight. Immunostaining was performed using the avidin-biotin complex $(\mathrm{ABC})$ procedure, including heat-induced epitope retrieval and enzymatic antigen retrieval procedures. Incubation was carried out overnight at $4{ }^{\circ} \mathrm{C}$ for Bcl-2 (clone 124; DAKO, Glostrup, Denmark, $1: 100$ ) and VEGF (VEGF-A20; Santa Cruz Biotechnology, Santa Cruz, CA, USA, $1: 100$ ), and in a moist chamber at $37^{\circ} \mathrm{C}$ for $1 \mathrm{~h}$ for p53 (clone DO-7; DAKO, Denmark, 1:100) and APAF-1 (NCL-APAF-1; Novocastra, Newcastle, UK, 1:100). Immunohistochemistry for EGFR (clone $3 \mathrm{C} 6,3 \mathrm{mg} \mathrm{ml}^{-1}$; Ventana Medical Systems, Tucson, AZ, USA) was performed using an autostainer according to manufacturer's instructions. Negative controls were treated identically, with primary antibodies omitted.

\section{Evaluation of immunohistochemistry}

Immunoreactivity was evaluated in a semi-quantitative manner from pretreatment biopsy specimens. The proportion of immunoreactive tumour cells over the total number of tumour cells by $5 \%$ increments $(0,5,10$, and so on up to $100 \%)$ was determined by three pathologists (A Lugli, JR Jass, S Hayashi) for EGFR and by four pathologists (CC Compton, A Lugli, JR Jass, RP Michel) for p53, Bcl-2, VEGF and APAF-1. This scoring method was previously found to be highly reproducible between pathologists (Zlobec et al, 2006a, 2007c). Only areas of invasive carcinoma were analysed. Protein expression was not evaluated in biopsies lacking sufficient tissue for immunohistochemical evaluation. Staining was assessed in the nucleus for p53 and in the cytoplasm for VEGF, Bcl-2 and APAF-1. Immunoreactivity for EGFR expression was assessed in both cytoplasm and/or membrane. Staining intensity was not evaluated.

\section{Statistical analysis}

Selection of cut-off scores for protein positivity Relevant cut-off scores for tumour positivity for each protein marker were obtained by performing receiver-operating characteristic (ROC) curve analysis (Zlobec et al, 2006b). Briefly, plots of sensitivity and (1-specificity) for complete pathologic tumour response were obtained for each marker and the $(0,1)$-criterion was used to select the threshold value, or protein expression score, above which expression was to be considered 'positive' (Bewick et al, 2004). In order to determine the reliability of the ROC curve-derived cut-off score, resampling of the data using 100 bootstrapped replications was performed for all proteins. To determine the discriminatory power of each marker for complete pathologic response, the area under the ROC curve (AUC), standard error (s.e.) and 95\% CI were obtained for each. The closer the AUC to 1.0 is, the greater the predictive power of the marker for complete tumour response.

\section{Association with clinicopathological features at the respective cut-offs}

The association of complete tumour response with both clinicopathological features and protein expression was analysed using logistic regression and where appropriate, with Fisher's Exact test. The $P$-values, odds ratio (OR) and $95 \% \mathrm{CI}$ for each analysis were obtained. A Bonferroni correction for multiple comparisons was performed. To maintain an overall type I error rate of 0.05 , each test of association with complete pathologic response was considered significant if $P<0.005$. All variables significant in univariate analysis were entered into a multiple logistic regression model. Statistical interactions between significant variables were 
tested. All analyses were carried out with SAS V9 (The SAS Institute, Cary, NC, USA).

\section{RESULTS}

\section{Clinicopathological features}

Patient characteristics are summarised in Table 1. Thirty-three $(31.7 \%)$ patients had a complete pathologic tumour response to

Table I Clinicopathological characteristics of rectal cancer patients treated with high-dose-rate brachytherapy

\begin{tabular}{|c|c|c|c|}
\hline \multirow[b]{2}{*}{ Clinicopathological feature } & \multirow{2}{*}{$\begin{array}{c}\text { Total } \\
n\end{array}$} & \multicolumn{2}{|c|}{ Frequency } \\
\hline & & $n$ & (\%) \\
\hline \multicolumn{4}{|l|}{ Sex } \\
\hline Female & 104 & 74 & 67.3 \\
\hline Male & & 36 & 32.7 \\
\hline \multicolumn{4}{|l|}{ Tumour grade (differentiation) } \\
\hline Well & 92 & 21 & 22.8 \\
\hline Moderate & & 67 & 72.8 \\
\hline Poor & & 4 & 4.4 \\
\hline \multicolumn{4}{|l|}{ Tumour response } \\
\hline Complete & 104 & 33 & 31.7 \\
\hline Partial & & 35 & 33.6 \\
\hline None & & 36 & 34.6 \\
\hline \multicolumn{4}{|l|}{ cT stage } \\
\hline cTI & 102 & 0 & 0 \\
\hline cT2 & & 2 & 2.0 \\
\hline cT3 & & 96 & 94.1 \\
\hline cT4 & & 4 & 3.9 \\
\hline \multicolumn{4}{|l|}{ PT stage } \\
\hline PTO & 80 & 31 & 38.8 \\
\hline PTI & & 12 & 15.0 \\
\hline PT2 & & 17 & 21.2 \\
\hline pT3 & & 20 & 25.0 \\
\hline
\end{tabular}

preoperative HDREB. Seventy-one $(68.3 \%)$ were found to have residual carcinoma, including 35 patients $(34.3 \%)$ who were considered as partial responders due to the presence of microfoci of residual carcinoma. Ninety-six $(94.1 \%)$ patients were preoperatively staged as cT3. pT stage was available for 80 patients, of which $31(38.8 \%)$ were pT0, $12(15.0 \%)$ were downstaged to pT1, $17(21.3 \%)$ were pT2 and 20 cases $(25.0 \%)$ were pT3.

\section{Selection of cut-off scores based on ROC curve analysis}

Cut-off scores were determined to be $50 \%$ for p53, 20\% for VEGF, Bcl-2 and EGFR and 10\% for APAF-1. Tumours with scores above the obtained cut-off values were considered positive for the expression of the protein. The corresponding AUCs (95\% CI) are listed in Table 2. AUCs were the largest for EGFR $(0.66$ $(0.54-0.78))$ and VEGF $(0.64(0.51-0.77)$ indicating that the discriminatory power for complete response was the greatest for these two markers.

\section{Univariate analysis}

The association of protein expression with complete pathologic response (Table 2) demonstrated that negative VEGF expression $(P$-value $=0.004$, OR $(95 \%$ CI $)=0.23(0.09-0.63))$ and EGFR positivity $(P$-value $=0.003$, OR $(95 \% \mathrm{CI})=5.78(1.85-18.07))$ were significantly associated with complete tumour response after correction for multiple comparisons while p53, APAF-1 and Bcl-2 demonstrated no predictive ability for the outcome. Loss of VEGF expression was associated with more than a 4.3 times greater chance of complete tumour response compared with VEGFpositive tumours, while EGFR positivity resulted in a 5.78 times increased odds of complete tumour regression. Representative immunostains of VEGF and EGFR are illustrated in Figure 1.

\section{Multivariable analysis}

VEGF and EGFR were entered into multivariable analysis. Eightyeight tumours could be evaluated, of which $27(31 \%)$ had a complete pathologic response. Loss of VEGF $(P$-value $=0.009$; OR $(95 \% \mathrm{CI})=0.24(0.08-0.69))$ and positive EGFR $(P$-value $=0.01$ OR $(95 \% \mathrm{CI})=3.82(1.37-10.6))$ both demonstrated independent

Table 2 ROC curve-derived cut-off scores, area under the curve (AUC) and association of protein expression with complete pathologic response

\begin{tabular}{|c|c|c|c|c|c|c|}
\hline Cut-off score & AUC $(95 \% \mathrm{Cl})$ & Total (n) & No complete response, $n(\%)$ & Complete response, $n$ (\%) & $P$-value & OR $(95 \% \mathrm{Cl})$ \\
\hline $\begin{array}{l}\leqslant 50 \% \\
>50 \%\end{array}$ & $0.529(0.39-0.66)$ & 92 & $\begin{array}{ll}41 & (70.7) \\
22 & (64.7)\end{array}$ & $\begin{array}{l}17(29.3) \\
12(35.3)\end{array}$ & 0.359 & $1.55(0.61-3.96)$ \\
\hline \multicolumn{7}{|l|}{ VEGF } \\
\hline $\begin{array}{l}\leqslant 20 \% \\
>20 \%\end{array}$ & $0.64(0.5 \mid-0.77)$ & 89 & $\begin{array}{l}12(48.0) \\
49(76.6)\end{array}$ & $\begin{array}{l}13(52.0) \\
15(23.4)\end{array}$ & 0.004 & $0.23(0.09-0.63)$ \\
\hline $\begin{array}{l}\leqslant 20 \% \\
>20 \%\end{array}$ & $0.546(0.4 \mid-0.68)$ & 90 & $\begin{array}{l}49(72.1) \\
13(59.1)\end{array}$ & $\begin{array}{r}19(27.9) \\
9(40.9)\end{array}$ & 0.203 & $2.02(0.68-5.99)$ \\
\hline \multicolumn{7}{|l|}{ APAF-I } \\
\hline$\leqslant 10 \%$ & $0.538(0.4 \mid-0.67)$ & 88 & $40(71.4)$ & $16(28.6)$ & 0.137 & $2.07(0.8-5.38)$ \\
\hline$>10 \%$ & & & $20(62.5)$ & $12(37.5)$ & & \\
\hline
\end{tabular}

APAF- $\mathrm{I}=$ apoptosis protease-activating factor- $\mathrm{I}: \mathrm{Cl}=$ confidence interval; $\mathrm{EGFR}=$ epidermal growth factor receptor; $\mathrm{OR}=$ odds ratio; $\mathrm{ROC}=$ receiver-operating characteristic $\mathrm{VEGF}=$ vascular endothelial growth factor. 

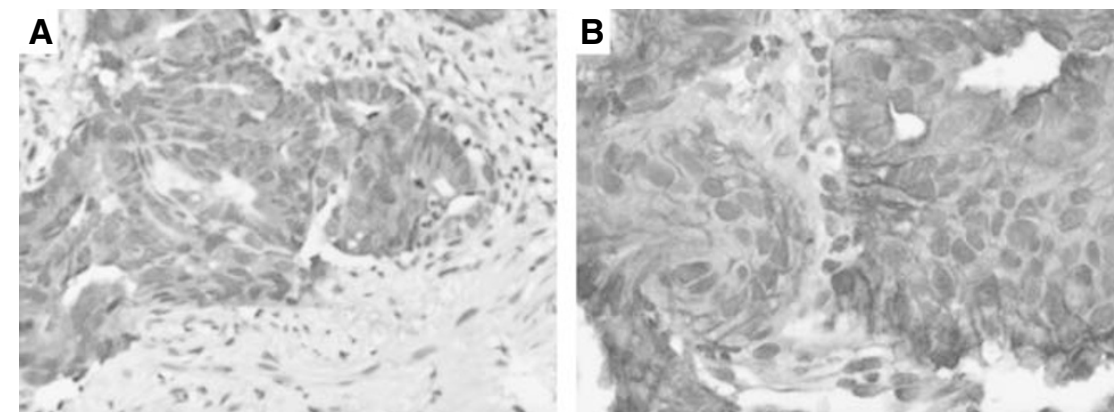

Figure I Representative immunostains of $\operatorname{VEGF}(\mathbf{A})$ and $\operatorname{EGFR}(\mathbf{B})$ from pretreatment rectal tumour biopsies.

Table 3 Multi-marker phenotype combinations of VEGF and EGFR in patients undergoing preoperative HDREB

\begin{tabular}{llccc}
\hline VEGF & EGFR & Total $(\boldsymbol{n})$ & $\begin{array}{c}\text { No complete } \\
\text { response }\end{array}$ & $\begin{array}{c}\text { Complete } \\
\text { response }\end{array}$ \\
\hline Negative & Negative & 15 & $7(46.7)$ & $8(53.3)$ \\
Negative & Positive & 9 & $5(55.6)$ & $4(44.4)$ \\
Positive & Negative & 34 & $32(94.1)$ & $2(5.9)$ \\
Positive & Positive & 30 & $17(56.7)$ & $13(43.3)$ \\
& Total & 88 & 61 & 27 \\
\hline
\end{tabular}

EGFR = epidermal growth factor receptor; HDREB = high-dose-rate endorectal brachytherapy; VEGF = vascular endothelial growth factor.

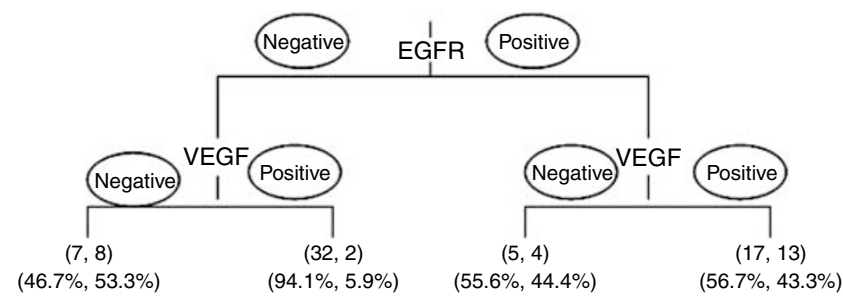

Figure 2 Decision tree summarising the frequency of complete tumour response with various multi-marker phenotype combinations. In first parentheses under each decision arm: number of patients with no complete response, number of patients with complete response. In second parentheses: proportion of patients with no complete response, proportion of patients with complete response.

predictive value for complete pathologic response. Multi-marker combinations of VEGF and EGFR were analysed and summarised in Table 3. Positive VEGF and negative EGFR expression were significantly associated with lack of complete pathologic response $(P<0.001)$ compared with all other multi-marker combinations. The odds of complete response were 12.8 for VEGF-negative and EGFR-positive tumours compared with VEGF-positive and EGFRnegative tumours. Moreover, of the 34 EGFR-negative cases, which simultaneously had VEGF positivity, $32(94.1 \%)$ had no complete pathologic response. These results are highlighted in Figure 2.

\section{DISCUSSION}

The aim of this study was to determine whether pretreatment expression levels of five immunohistochemical markers including p53, Bcl-2, APAF-1, VEGF and EGFR could predict complete pathologic tumour regression in patients with advanced rectal cancer undergoing preoperative radiotherapy. Our findings indicate that VEGF and EGFR are independent predictive factors and their combined analysis is highly predictive of complete pathologic response.
Prognostic or predictive studies evaluating immunohistochemical markers, including EGFR, have often yielded irreproducible results. Several sources of discrepancy have been recognised as contributing to the conflicting reports in the literature between similar studies, including methodological differences such as various fixation protocols and antibodies (Atkins et al, 2004; McShane et al, 2005). The interpretation of immunoreactivity is underlined as a major source of contradictory findings (Goldstein and Armin, 2001; Resnick et al, 2004; Spano et al, 2005; Kim et al, 2006; Li et al, 2006). In order to avoid the use of predetermined and often arbitrarily set cut-off values, we have previously shown how ROC curve analysis in conjunction with a resampling procedure can be systematically used to evaluate the protein expression of immunohistochemical tumour markers (Zlobec et al, 2007a). Along with a reproducible semi-quantitative scoring system, ROC curve analysis is a powerful method for selecting cutoff scores to describe tumour marker positivity for a specific clinical endpoint, such as tumour response. In addition, we have recently demonstrated that assessment of staining intensity between independent observers results in low to moderate interobserver agreement whereas the semi-quantitative evaluation of protein expression is highly reproducible between multiple observers and sufficient for providing the necessary information on the associations of protein markers with different clinicopathological endpoints (Zlobec et al, 2006a, 2007b, c).

By applying ROC curve derived cut-off scores to the immunohistochemical markers in this study, we found that VEGF negative tumours were more than four times more likely to undergo a complete tumour regression than their VEGF positive counterparts. Complete pathologic response was nearly six times more likely in EGFR-positive tumours compared with EGFR-negative cases. Moreover, analysis of multi-marker phenotypes of VEGF and EGFR expression identified a subgroup of VEGF-positive and EGFR-negative tumours that were highly resistant to treatment.

VEGF is a potent angiogenic promoter required for the full execution of angiogenesis. VEGF receptor signalling has been shown to have effects on endothelial cell proliferation, migration, survival and vascular permeability (Roskoski, 2007). In addition, urokinase plasminogen activator, tissue plasminogen activator and matrix metalloproteinases are induced by upregulation of VEGF. These proteins function to degrade the basement membrane and extracellular matrix, providing a scaffold for proliferating, migrating and extravasating endothelial cells (Ferrara et al, 2003). The result of tumour angiogenesis is a newly formed vasculature with 'leaky', disorganised vessels, increased interstitial pressure and chaotic blood flow, which decreases the efficiency of radiotherapy (Willett et al, 2006; Roskoski, 2007). In 1971, Folkman (1971) hypothesised that blocking angiogenesis in tumours could be used a method of treatment for patients with cancer. Pharmacological agents designed to block VEGF or VEGF receptor signalling are currently in various phases of clinical trials and have demonstrating promising results (Kowanetz and Ferrara, 2006; Roskoski, 2007; Willett et al, 2007). The VEGF blockade results in 
'normalisation' of the vasculature, decreased interstitial pressure and vascular permeability, thereby potentiating the effects of radiotherapy by increasing oxygen transport to tumour cells and facilitating the delivery of chemotherapeutic agents to the target tumour (Willett et al, 2006). In our study, VEGF positivity was strongly associated with a more radio-resistant phenotype.

In colorectal cancer, VEGF is associated with tumour aggressiveness, poor survival, local failure and the presence of metastatic disease (Giatromanolaki et al, 2006). Giralt et al (2007) demonstrated that VEGF positivity is an indicator of poor disease-free survival following preoperative radiochemotherapy, while Nozue et al (2001) described an association between post-treatment VEGF overexpression and distant metastasis. Qiu et al (2000) found no correlation between pretreatment VEGF expression and tumour response in 72 patients undergoing long-course neoadjuvant radiotherapy. In a previous work on the same, yet smaller series of patients, we not only identified VEGF but also Bcl-2 as significant predictors of tumour regression (Zlobec et al, 2005). Bcl-2-negative tumours experienced a partial or complete tumour regression more often than Bcl-2-positive cases. This protein, however, was not associated with complete tumour regression in this study, a discrepancy that is likely due to the different clinical endpoints evaluated in our previous and current works. These results suggest a possible role for $\mathrm{Bcl}-2$ in tumour regression, which requires further elucidation. To our knowledge, the present study is the first to have evaluated complete pathologic response and pretreatment VEGF expression in rectal tumours. Our results clearly demonstrate that patients with VEGF-negative tumours before treatment should be considered candidates for preoperative radiotherapy.

Although the prognostic role of EGFR has been frequently investigated, only few studies have assessed the predictive value of pretreatment EGFR expression in preoperative radio- or radiochemotherapy. Recent reports are conflicting. While Giralt et al (2005) found a significant association between EGFR overexpression and a lack of complete pathologic tumour regression to preoperative radiotherapy, Bertolini et al (2007) reported no such result. The findings of our study indicate that pretreatment EGFR expression is an indicator of complete pathologic response and strongly supports the treatment of these patients with preoperative radiotherapy. Recently Jonker and co-workers assessed the value of the anti-EGFR therapy cetuximab on a large cohort of 572 patients with advanced EGFR-expressing colorectal cancers who failed to respond to previous chemotherapy, and found a significant improvement in overall survival in these patients. Anti-EGFR therapy may further improve clinical outcome in our series our EGFR-positive, and more radiosensitive patients treated with HDREB (Jonker et al, 2007).

Although our results, which indicate improved outcome in patients with positive EGFR, appear to conflict with the majority of reports in colorectal cancer, our findings are in line with previous studies in head and neck squamous cell carcinoma (HNSCC) using moderately accelerated or hyperfractionated accelerated radiotherapy. Eriksen et al (2005) investigated 803 patients randomised to 5 vs 6 fractions per week of radiotherapy. They found that high-EGFR tumours responded better to moderately accelerated radiotherapy compared with EGFR-low tumours, and determined that response to accelerated fractionation may be predicted by high EGFR expression in pretreatment tissue samples. Bentzen and co-workers performed IHC on 304 patients randomised to receive CHART vs conventionally fractionated radiotherapy. They concluded that there was a significant benefit from strongly accelerated CHART in patients with high EGFR expression and no benefit in patients with a low EGFR index (Bentzen et al, 2005). These results suggest that the predictive value of EGFR to radiotherapy may be dependent on the dose fractionation regimen.

In our combined analysis of VEGF and EGFR expression, both markers had independent value for predicting a complete pathologic tumour regression. Simultaneous VEGF-positive and EGFR-negative expression was associated with a lack of complete tumour regression in more than $94 \%$ of cases and a 12 -folddecreased odds of response compared with EGFR-positive and VEGF-negative tumours. A relationship between EGFR and VEGF has previously been established. Not only do both proteins share the same intracellular signalling pathways (Roberts and Der, 2007), but several preclinical studies have provided evidence for either direct or indirect angiogenic effects of EGFR signalling (Ciardiello et al, 2006). EGFR has additionally been reported to upregulate VEGF expression (Ciardiello et al, 2006). Recently Eriksen et al (2005) demonstrated that EGFR tyrosine kinase inhibitors decrease VEGF expression by both HIF- $1 \alpha$-independent and -dependent mechanisms. Although interrelated, the contribution of VEGF and EGFR to angiogenesis appears to arise through distinct mechanisms, thereby warranting the simultaneous blockade of both proteins for the treatment of patients with rectal cancer (Tabernero, 2007).

We acknowledge that preoperative HDREB remains an experimental approach that is presently being considered for a randomised trial. At the present time, different radiation schedules are used: in northern Europe, $25 \mathrm{~Gy}$ in five fractions (short course) is commonly applied, whereas $45 \mathrm{~Gy}$ in 25 fractions (long course) with chemotherapy is preferred in southern Europe and North America. Bujko et al (2006) randomised 310 patients with cT3 rectal cancer to $5 \mathrm{~Gy} \times 5$, followed by surgery or conventional preoperative $50.4 \mathrm{~Gy}$ plus bolus 5FU1leucovorin daily over 5 weeks, followed by surgery and reported similar local control and survival results. The ability to predict complete pathologic response or sensitivity to radiation based on IHC would have a significant impact on the selection of patients for preoperative radiotherapy or chemoradiation therapy schedules.

In this study, negative VEGF and positive EGFR expression were predictive of complete pathologic response to preoperative radiotherapy in patients with advanced rectal cancer. In addition, our findings have identified a subgroup of VEGF-positive and EGFRnegative tumours, which are more resistant to radiotherapy and should perhaps be considered candidates for innovative neoadjuvant combined modalities.

\section{REFERENCES}

Atkins D, Reiffen KA, Tegtmeier CL, Winther H, Bonato MS, Storkel S (2004) Immunohistochemical detection of EGFR in paraffin-embedded tumor tissues: variation in staining intensity due to choice of fixative and storage time of tissue sections. J Histochem Cytochem 52: 893-901

Bentzen SM, Atasoy BM, Daley FM, Dische S, Richman PI, Saunders MI, Trott KR, Wilson GD (2005) Epidermal growth factor receptor expression in pretreatment biopsies from head and neck squamous cell carcinoma as a predictive factor for a benefit from accelerated radiation therapy in a randomized controlled trial. J Clin Oncol 23: 5560-5567
Bertolini F, Bengala C, Losi L, Pagano M, Iachetta F, Dealis C, Jovic G, Depenni R, Zironi S, Falchi AM, Luppi G, Conte PF (2007) Prognostic and predictive value of baseline and posttreatment molecular marker expression in locally advanced rectal cancer treated with neoadjuvant chemoradiotherapy. Int J Radiat Oncol Biol Phys 68: 1455-1461

Bewick V, Cheek L, Ball J (2004) Statistics review 13: receiver operating characteristic curves. Crit Care 8: 508-512

Brooks S, Glynne-Jones R, Novell R, Harrison M, Brown K, Makris A (2006) Short course continuous, hyperfractionated, accelerated radiation 
therapy (CHART) as preoperative treatment for rectal cancer. Acta Oncol 45: $1079-1085$

Bujko K, Nowacki MP, Nasierowska-Guttmejer A, Michalski W, Bebenek M, Kryj M (2006) Long-term results of a randomized trial comparing preoperative short-course radiotherapy with preoperative conventionally fractionated chemoradiation for rectal cancer. Br J Surg 93: 1215-1223

Ciardiello F, Troiani T, Bianco R, Orditura M, Morgillo F, Martinelli E, Morelli MP, Cascone T, Tortora G (2006) Interaction between the epidermal growth factor receptor (EGFR) and the vascular endothelial growth factor (VEGF) pathways: a rational approach for multi-target anticancer therapy. Ann Oncol 17: vii109-vii114

Colorectal Cancer Collaborative Group (2001) Adjuvant radiotherapy for rectal cancer: a systematic overview of 8,507 patients from 22 randomised trials. Lancet 358: $1291-1304$

Das P, Skibber JM, Rodriguez-Bigas MA, Feig BW, Chang GJ, Wolff RA, Eng C, Krishnan S, Janjan NA, Crane CH (2007) Predictors of tumor response and downstaging in patients who receive preoperative chemoradiation for rectal cancer. Cancer 109: $1750-1755$

den Dulk M, Marijnen CA, Putter H, Rutten HJ, Beets GL, Wiggers T, Nagtegaal ID, van de Velde CJ (2007) Risk factors for adverse outcome in patients with rectal cancer treated with an abdominoperineal resection in the total mesorectal excision trial. Ann Surg 246: 83-90

Eriksen JG, Steiniche T, Overgaard J (2005) The influence of epidermal growth factor receptor and tumor differentiation on the response to accelerated radiotherapy of squamous cell carcinomas of the head and neck in the randomized DAHANCA 6 and 7 Study. Radiother Oncol 74: $93-100$

Eriksen MT, Wibe A, Haffner J, Wiig JN (2007) Prognostic groups in 1,676 patients with $\mathrm{T} 3$ rectal cancer treated without preoperative radiotherapy. Dis Colon Rectum 50: $156-167$

Ferrara N, Gerber HP, LeCouter J (2003) The biology of VEGF and its receptors. Nat Med 9: 669-676

Folkman J (1971) Tumor angiogenesis: therapeutic implications. N Engl J Med 285: $1182-1186$

Ghadimi BM, Grade M, Difilippantonio MJ, Varma S, Simon R, Montagna C, Fuzesi L, Langer C, Becker H, Liersch T, Ried T (2005) Effectiveness of gene expression profiling for response prediction of rectal adenocarcinomas to preoperative chemoradiotherapy. J Clin Oncol 23: 1826-1838

Giatromanolaki A, Sivridis E, Koukourakis MI (2006) Angiogenesis in colorectal cancer: prognostic and therapeutic implications. Am J Clin Oncol 29: 408-417

Giralt J, de las Heras M, Cerezo L, Eraso A, Hermosilla E, Velez D, Lujan J, Espin E, Rosello J, Majo J, Benavente S, Armengol M, de Torres I (2005) The expression of epidermal growth factor receptor results in a worse prognosis for patients with rectal cancer treated with preoperative radiotherapy: a multicenter, retrospective analysis. Radiother Oncol 74: $101-108$

Giralt J, Navalpotro B, Hermosilla E, de Torres I, Espin E, Reyes V, Cerezo L, de Las Heras M, Ramon YCS, Armengol M, Benavente S (2007) Prognostic significance of vascular endothelial growth factor and cyclooxygenase- 2 in patients with rectal cancer treated with preoperative radiotherapy. Oncology 71: $312-319$

Goldstein NS, Armin M (2001) Epidermal growth factor receptor immunohistochemical reactivity in patients with American Joint Committee on Cancer Stage IV colon adenocarcinoma: implications for a standardized scoring system. Cancer 92: 1331-1346

Jonker DJ, O'Callaghan CJ, Karapetis CS, Zalcberg JR, Tu D, Au HJ, Berry SR, Krahn M, Price T, Simes RJ, Tebbutt NC, van Hazel G, Wierzbicki R, Langer C, Moore MJ (2007) Cetuximab for the treatment of colorectal cancer. N Engl J Med 357: 2040 - 2048

Kapiteijn E, Marijnen CA, Nagtegaal ID, Putter H, Steup WH, Wiggers T, Rutten HJ, Pahlman L, Glimelius B, van Krieken JH, Leer JW, van de Velde CJ (2001) Preoperative radiotherapy combined with total mesorectal excision for resectable rectal cancer. $N$ Engl $J$ Med 345: $638-646$

Kim IJ, Lim SB, Kang HC, Chang HJ, Ahn SA, Park HW, Jang SG, Park JH, Kim DY, Jung KH, Choi HS, Jeong SY, Sohn DK, Kim DW, Park JG (2007) Microarray gene expression profiling for predicting complete response to preoperative chemoradiotherapy in patients with advanced rectal cancer. Dis Colon Rectum 50(9): $1342-1353$

Kim JS, Kim JM, Li S, Yoon WH, Song KS, Kim KH, Yeo SG, Nam JS, Cho MJ (2006) Epidermal growth factor receptor as a predictor of tumor downstaging in locally advanced rectal cancer patients treated with preoperative chemoradiotherapy. Int J Radiat Oncol Biol Phys 66: $195-200$
Kowanetz M, Ferrara N (2006) Vascular endothelial growth factor signaling pathways: therapeutic perspective. Clin Cancer Res 12: 5018-5022

Kuo LJ, Liu MC, Jian JJ, Horng CF, Cheng TI, Chen CM, Fang WT, Chung YL (2007) Is final TNM staging a predictor for survival in locally advanced rectal cancer after preoperative chemoradiation therapy? Ann Surg Oncol 14(10): 2766-2772

Larsen SG, Wiig JN, Dueland S, Giercksky KE (2007) Prognostic factors after preoperative irradiation and surgery for locally advanced rectal cancer. Eur J Surg Oncol [e-pub ahead of print]

Li S, Kim JS, Kim JM, Cho MJ, Yoon WH, Song KS, Yeo SG, Kim JS (2006) Epidermal growth factor receptor as a prognostic factor in locally advanced rectal-cancer patients treated with preoperative chemoradiation. Int J Radiat Oncol Biol Phys 65: 705-712

Lin LC, Lee HH, Hwang WS, Li CF, Huang CT, Que J, Lin KL, Lin FC, Lu CL (2006) p53 and p27 as predictors of clinical outcome for rectal-cancer patients receiving neoadjuvant therapy. Surg Oncol 15: 211-216

Lopez-Crapez E, Bibeau F, Thezenas S, Ychou M, Simony-Lafontaine J, Thirion A, Azria D, Grenier J, Senesse P (2005) p53 status and response to radiotherapy in rectal cancer: a prospective multilevel analysis. $\mathrm{Br} \mathrm{J}$ Cancer 92: $2114-2121$

Martling A, Holm T, Johansson H, Rutqvist LE, Cedermark B (2001) The Stockholm II trial on preoperative radiotherapy in rectal carcinoma: long-term follow-up of a population-based study. Cancer 92: $896-902$

McShane LM, Altman DG, Sauerbrei W, Taube SE, Gion M, Clark GM (2005) Reporting recommendations for tumour MARKer prognostic studies (REMARK). Br J Cancer 93: 387-391

Nozue M, Isaka N, Fukao K (2001) Over-expression of vascular endothelial growth factor after preoperative radiation therapy for rectal cancer. Oncol Rep 8: 1247 - 1249

O'Connell JB, Maggard MA, Ko CY (2004) Colon cancer survival rates with the new American Joint Committee on Cancer sixth edition staging. J Natl Cancer Inst 96: 1420-1425

Pore N, Jiang Z, Gupta A, Cerniglia G, Kao GD, Maity A (2006) EGFR tyrosine kinase inhibitors decrease VEGF expression by both hypoxiainducible factor (HIF)-1-independent and HIF-1-dependent mechanisms. Cancer Res 66: 3197-3204

Qiu H, Sirivongs P, Rothenberger M, Rothenberger DA, Garcia-Aguilar J (2000) Molecular prognostic factors in rectal cancer treated by radiation and surgery. Dis Colon Rectum 43: 451-459

Resnick MB, Routhier J, Konkin T, Sabo E, Pricolo VE (2004) Epidermal growth factor receptor, c-MET, beta-catenin, and p53 expression as prognostic indicators in stage II colon cancer: a tissue microarray study. Clin Cancer Res 10: 3069-3075

Roberts PJ, Der CJ (2007) Targeting the Raf-MEK-ERK mitogen-activated protein kinase cascade for the treatment of cancer. Oncogene 26: $3291-3310$

Rodel C, Martus P, Papadoupolos T, Fuzesi L, Klimpfinger M, Fietkau R, Liersch T, Hohenberger W, Raab R, Sauer R, Wittekind C (2005) Prognostic significance of tumor regression after preoperative chemoradiotherapy for rectal cancer. J Clin Oncol 23: 8688-8696

Roskoski Jr R (2007) Vascular endothelial growth factor (VEGF) signaling in tumor progression. Crit Rev Oncol Hematol 62: 179-213

Smith FM, Reynolds JV, Miller N, Stephens RB, Kennedy MJ (2006) Pathological and molecular predictors of the response of rectal cancer to neoadjuvant radiochemotherapy. Eur J Surg Oncol 32: 55-64

Spano JP, Lagorce C, Atlan D, Milano G, Domont J, Benamouzig R, Attar A, Benichou J, Martin A, Morere JF, Raphael M, Penault-Llorca F, Breau JL, Fagard R, Khayat D, Wind P (2005) Impact of EGFR expression on colorectal cancer patient prognosis and survival. Ann Oncol 16: 102-108

Swedish Rectal Cancer Trial Group (1997) Improved survival with preoperative radiotherapy in resectable rectal cancer. Swedish Rectal Cancer Trial. $N$ Engl J Med 336: 980 - 987

Tabernero J (2007) The role of VEGF and EGFR inhibition: implications for combining anti-VEGF and anti-EGFR agents. Mol Cancer Res 5: $203-220$

Vuong T, Belliveau PJ, Michel RP, Moftah BA, Parent J, Trudel JL, Reinhold C, Souhami L (2002) Conformal preoperative endorectal brachytherapy treatment for locally advanced rectal cancer: early results of a phase I/II study. Dis Colon Rectum 45: 1486-1493; discussion 1493-5

Vuong T, Devic S, Podgorsak E (2007) High dose rate endorectal brachytherapy as a neoadjuvant treatment for patients with resectable rectal cancer. Clin Oncol (R Coll Radiol) 19(9): 701-705

Willett CG, Duda DG, di Tomaso E, Boucher Y, Czito BG, Vujaskovic Z, Vlahovic G, Bendell J, Cohen KS, Hurwitz HI, Bentley R, Lauwers GY, 
Poleski M, Wong TZ, Paulson E, Ludwig KA, Jain RK (2007) Complete pathological response to bevacizumab and chemoradiation in advanced rectal cancer. Nat Clin Pract Oncol 4: 316-321

Willett CG, Kozin SV, Duda DG, di Tomaso E, Kozak KR, Boucher Y, Jain RK (2006) Combined vascular endothelial growth factor-targeted therapy and radiotherapy for rectal cancer: theory and clinical practice. Semin Oncol 33: S35-S40

Wolpin BM, Meyerhardt JA, Mamon HJ, Mayer RJ (2007) Adjuvant treatment of colorectal cancer. CA Cancer J Clin 57: 168-185

Wong RK, Tandan V, De Silva S, Figueredo A (2007) Pre-operative radiotherapy and curative surgery for the management of localized rectal carcinoma. Cochrane Database Syst Rev 18(2): CD002102

Zlobec I, Steele R, Michel RP, Compton CC, Lugli A, Jass JR (2006a) Scoring of p53, VEGF, Bcl-2 and APAF-1 immunohistochemistry and interobserver reliability in colorectal cancer. Mod Pathol 19: $1236-1242$
Zlobec I, Steele R, Nigam N, Compton CC (2005) A predictive model of rectal tumor response to preoperative radiotherapy using classification and regression tree methods. Clin Cancer Res 11: 5440-5443

Zlobec I, Steele R, Terracciano L, Jass JR, Lugli A (2007a) Selecting immunohistochemical cut-off scores for novel biomarkers of progression and survival in colorectal cancer. J Clin Pathol 60: 1112-1116

Zlobec I, Steele R, Terracciano L, Jass JR, Lugli A (2006b) Selecting immunohistochemical cut-off scores for novel biomarkers of progression and survival in colorectal cancer. J Clin Pathol 60(10): 1112-1116

Zlobec I, Terracciano L, Jass JR, Lugli A (2007b) Value of staining intensity in the interpretation of immunohistochemistry for tumor markers in colorectal cancer. Virchows Arch 451: 763 -769

Zlobec I, Vuong T, Hayashi S, Haegert D, Tornillo L, Terracciano L, Lugli A, Jass J (2007c) A simple and reproducible scoring system for EGFR in colorectal cancer: application to prognosis and prediction of response to preoperative brachytherapy. Br J Cancer 96: 793-800 